\title{
Prof. Dr. Dr. h.c. mult. Gottfried Otto Helmut Naumann, Co-Founder of Ophthalmic Research: An Ophthalmological Giant Leaves the Stage
}

On June 5, 2021, Prof. Dr. Dr. h.c. mult. Gottfried Otto Helmut Naumann passed away in Erlangen after a long illness. Prof. Naumann was not only the former chairman of the Department of Ophthalmology at the University of Erlangen-Nuremberg, but also the past president of the International Council of Ophthalmology, one of the founding fathers of ophthalmic pathology in Europe but also the co-founder of the journal Ophthalmic Research.

Prof. Naumann was born in Wiesbaden on April 25, 1935. He spent his childhood in Saxony and studied medicine at the University of Leipzig from 1952 to 1957. Afterwards he fled from Eastern Germany and established himself in the western part in September 1958. He then moved to Hamburg to receive his ophthalmological training with Prof. Hans Sautter at the University Eye Hospital in Hamburg (1961-1964). Subsequently Prof. Naumann did a fellowship in the USA with Prof. Lorenz E. Zimmermann (1965-1966) at the Armed Forces Institute of Pathology (AFIP) in Washington. This significantly influenced his later career as one of the leading ophthalmic pathologists worldwide.

After returning to Hamburg and his habilitation in 1968, Prof. Naumann received a call to become chairman at the University Eye Department in Tübingen in 1975. In 1980 he became the next chairman at the University Eye Hospital in Erlangen-Nuremberg in Erlangen. For the following 23 years, he was chairman of the Eye De-

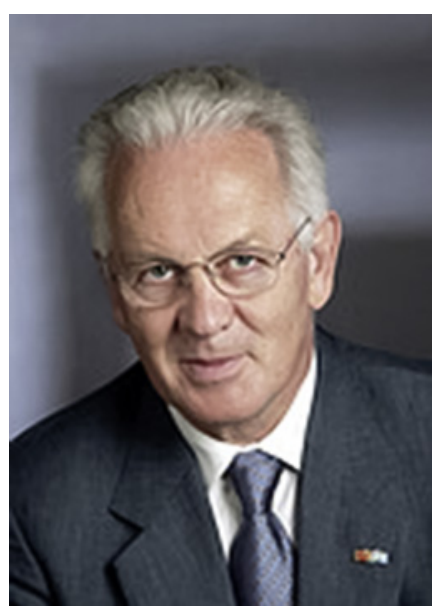

Prof. Dr. Dr. h.c. mult. Gottfried Otto Helmut Naumann

partment and formed its international reputation. Prof. Naumann was an enthusiastic clinician and scientist and a very prolific writer with more than 600 peer-reviewed publications and numerous books, especially Pathology of the Eye and Applied Pathology for Ophthalmic Microsurgeons. Prof. Naumann received numerous honors, medals, lectures, memberships and awards. Just to mention a few, he gave the Bowman Lecture, received the most prestigious award of the German Ophthalmological Society, the Albrecht von Graefe Medal in 2006, he became member of the German National Academy of Sciences Leop-
(C) 2021 The Author(s)

Published by S. Karger AG, Basel

This is an Open Access article licensed under the Creative Commons Attribution-NonCommercial-4.0 International License (CC BY-NC) (http://www.karger.com/Services/OpenAccessLicense), applicable to the online version of the article only. Usage and distribution for commercial purposes requires written permission. 
oldina in 1998 and he received numerous honorary medical doctor degrees, for example at the Semmelweis University in Budapest in 2000.

Prof. Naumann was in several aspects a giant in the field and accomplished this with an enormous enthusiasm, workload and activity. Just to mention a few special areas of excellence:

- Ophthalmic pathology: Prof. Naumann - having trained at the AFIP in Washington - was instrumental to build up ophthalmic pathology in Germany and in Europe. In 1972, he founded the German Ophthalmic Pathology Society which has since held annual meetings forming generations of ophthalmic pathologists. He wrote the international standard textbook of ophthalmic pathology Pathology of the Eye and later Applied Pathology for Ophthalmic Microsurgeons and had a tremendous impact on ophthalmic pathology especially with application to the clinic. Just as an example he and Prof. Ursula Schlötzer-Schrehardt contributed enormously to unraveling ocular and systemic aspects of pseudoexfoliation syndrome and glaucoma. Based on his ophthalmic pathological knowledge he developed new surgical approaches, for example the technique of block excision for ciliary body tumors and the nonmechanical excimer laser technique for penetrating keratoplasty.

- Translational science: Prof. Naumann was a role model for clinician scientists in combining clinical ophthalmology and basic research to address unmet clinical needs. He motivated people from within the field and outside ophthalmology to join in and address important unmet questions. Based on this he was successful in obtaining a Research Unit for glaucoma and later the only Collaborative Research Group ("Sonderforschungsbereich" 539) of the German Research Foundation DFG in the field of ophthalmology (devoted to the topic of glaucoma and pseudoexfoliation syndrome).

- Mentor and teacher: being a tremendously active, encouraging and successful teacher and mentor, Prof. Naumann trained overall 8 chairmen of departments of ophthalmology in Germany and had overall 24 " $\mathrm{Ha}$ bilitanden." Most of the ophthalmologists and scientists he trained view themselves as his "students" and kept lifelong contact with their mentor. We all remember numerous quotes and sentences from Prof. Naumann.
- International and European activity: as a convinced fighter for the European idea, he founded and led the European University Professors of Ophthalmology association, was president of the European Board of Ophthalmology and later on moved to the international field to become the president of the International Council of Ophthalmology (1998-2002) and president of the International Federation of Ophthalmological Societies. He was also instrumental to bring the World Ophthalmological Congress 2010 to Berlin and had tremendous impact on the international perception of European and German ophthalmology. In addition, Prof. Naumann was actively involved in helping to integrate Eastern European Societies of Ophthalmology after the falling of the wall.

- Philanthropy: Prof. Naumann and his wife together supported ophthalmology in many ways. They not only supported ophthalmology locally, but also set up the "Gottfried and Lieselotte Naumann Foundation," e.g. to support the International Council of Ophthalmology's Ophthalmic Pathology Award, one of the most prestigious awards of ophthalmology, which will be given for the 5th time at the 38th meeting of the World Ophthalmological Congress 2022 in Melbourne.

- Prof. Naumann as editor: together with Prof. O. Hockwin from Bonn and Prof. D. Cole from London, Prof. Naumann founded Ophthalmic Research in 1970 and thereby established this prestigious journal for translational research in ophthalmology, which has recently celebrated its 50th anniversary. Furthermore, he had the chairmanship of the oldest continuously published journal of ophthalmology, the Klinische Monatsblätter für Augenheilkunde, which he and his wife led together for decades.

With Prof. Naumann we lose a truly special leader in the field, an impressive ophthalmologist, innovative microsurgeon, scientist, mentor, editor and advocate for ophthalmology and philanthropist supporting our subspecialty. We will keep him in our memory and continue his "fight against blindness" (quote Naumann).

Prof. Dr. med. Claus Cursiefen, FEBO, FARVO, ML, Chairman Department of Ophthalmology, University of Cologne, Germany 